\title{
(e) interface
}

comunicação, saúde, educação

https://www.interface.org.br

eISSN 1807-5762

\section{Entrevistas}

\section{Por uma Antropologia da Saúde politicamente posicionada: entrevista com Chiara Pussetti}

For a politically positioned Anthropology of Health: an interview with Chiara Pussetti

Por una Antropología de la Salud políticamente posicionada: una entrevista con Chiara Pussetti

Lucas Pereira de Melo(a)

$<$ lpmelo@usp.br> (iD

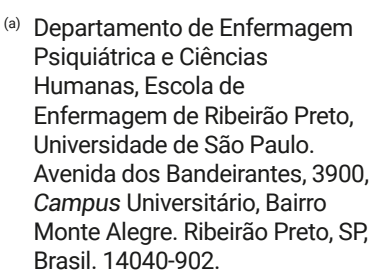

(a) Departamento de Enfermagem Psiquiátrica e Ciências Humanas, Escola de Enfermagem de Ribeirão Preto, Universidade de São Paulo.

Avenida dos Bandeirantes, 3900 Campus Universitário, Bairro Monte Alegre. Ribeirão Preto, $\mathrm{SP}$ Brasil. 14040-902.

Palavras-chave: Antropologia da Saúde. Emoções. Corpo. Processo saúdedoença. Melhoramento biomédico.

Keywords: Anthropology of Health. Emotions. Body. Health-disease process. Biomedical enhancement.

Palabras clave: Antropología de la Salud. Emociones. Cuerpo. Proceso salud-enfermedad. Refuerzo biomédico.

Entre janeiro e fevereiro de 2020, realizei uma estadia de curta duração no Instituto de Ciências Sociais da Universidade de Lisboa (ICS/ULisboa), Portugal, período no qual trabalhei com Chiara Pussetti, antropóloga, professora e investigadora auxiliar do ICS/ ULisboa. Realizada na manhã ensolarada e fria de 7 de fevereiro

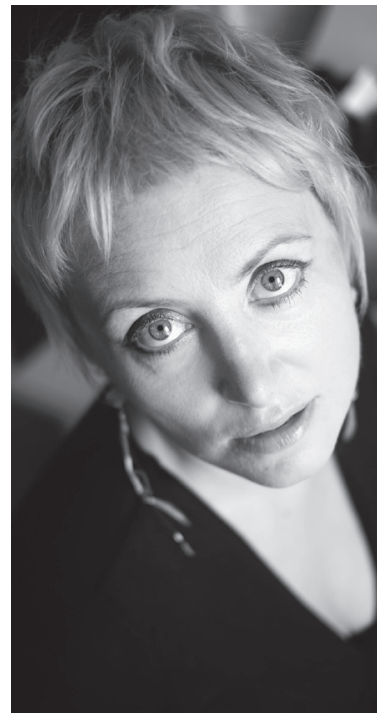


de 2020 em um café lisboeta, o Brick Café Lisboa, situado em uma encruzilhada formada pela Rua de Mozambique com a Rua do Forno de Tijolo, no bairro Anjos, esta entrevista destaca não só a trajetória intelectual, acadêmica e profissional de Chiara, como também reivindica um estatuto político, engajado, posicionado à Antropologia da Saúde.

Em tempos nos quais as Ciências Sociais, em geral, e a Antropologia, em particular, têm sido fortemente atacadas em contextos políticos de recrudescimento de governos autoritários - como é o caso do Brasil -, esta entrevista nos instiga a pensar, a investir e a criar ações que negritam a vocação dessas disciplinas acadêmicas de refletir sobre fenômenos sociais e experiências de sujeito localizadas, como também de abrir um leque de possibilidades para publicização dos diálogos e da coprodução de conhecimentos que, desde sempre, realizamos com as pessoas no fazer etnográfico.

Dali de onde conversávamos, não imaginávamos que naquele ano - no mês seguinte a Organização Mundial de Saúde declarou a pandemia de Covid-19 - as Ciências Sociais em todo o mundo seriam instadas a refletir e a participar da formulação de açôes políticas em diversos setores sociais voltadas ao enfrentamento da pandemia.

Nosso diálogo parecia antecipar muitas discussões com as quais nos veríamos, semanas depois, envoltos em nossos contextos de vida, de pesquisa e de trabalho. Fez-se isso ao problematizarmos temas candentes nesses últimos meses de pandemia tanto no Brasil quanto em Portugal, chamados que fomos a tentar compreender as múltiplas escalas (global, nacionais, locais), faces, dores, políticas que, de tanto nos aproximar, nos distanciam e particularizam experiências e representaçóes de corpo, saúde-doença, cuidado, ação estatal, ciência, risco e segurança nesses tempos pandêmicos. Temas que já nos acompanham há anos, mas que sempre se remodelam, se reconfiguram e, por nos surpreender, também nos convidam e nos mobilizam à reflexão antropológica e “mantém a tradição da eterna juventude das Ciências Sociais" (p. 387), como bem nos lembrou Peirano ${ }^{1}$, inspirada em Max Weber.

Chiara, sabemos que os percursos formativos em Antropologia têm caminhos bastante particulares, a depender do país onde ocorrem. Podes me contar como “chegastes” à Antropologia (ou como ela "chegou” a ti) e quais as inflexóes desse "encontro" na construção da tua trajetória intelectual, acadêmica e profissional?

Eu sou licenciada em Filosofia Teorética pela Universidade de Turim, na Itália. Lá não existem cursos de graduação em Antropologia. Depois, fiz o mestrado em Antropologia e Ciências Humanas. Naquela altura, o departamento ao qual estava vinculada era quase completamente africanista. Foi com essa Antropologia com a qual tive, a primeira vez, contato e, possivelmente devido à minha idade à época, fiquei fascinada pela possibilidade de compreender grandes questões relativas à Humanidade. Ainda na graduação, consegui um trabalho voluntário em um hospital em Guiné-Bissau, nas associações de intervenção comunitária. Durante o trabalho no hospital, aprendi a falar crioulo e português. Eu vivia com jovens artistas locais que me apresentaram um culto de possessão feminina, no qual todas as mulheres do povo Bijagós incorporavam os espíritos dos homens que faleceram antes de ter completado o percurso de iniciação. A despeito da literatura clássica da Antropologia, o caso dos Bijagós chamou-me a atenção, 
especialmente por se tratar de possessão coletiva entre mulheres: durante as fases de incorporação, o que pode durar até seis meses, as mulheres deixam completamente performances e atividades vinculadas ao que denominamos de "feminino" e assumem uma identidade "masculina". Esse culto de possessão feminina terminou por se constituir no tema da minha primeira pesquisa, cujo título foi "Uruté arebok: le piroghe d'anime. Culto di possessione e maternità simbolica tra i Bijagó della Guinea Bissau”. Fiz o doutoramento também na Universidade de Turim, onde começava a se desenvolver a Antropologia Médica e do Corpo, o que era interessante para mim porque pesquisava Antropologia das Emoções entre o povo Bijagós. A tese de doutoramento foi defendida em 2003 e teve por título "Persona, emozioni e morale tra i Bijagó di Bubaque (Guinea Bissau)". Da tese surgiu o meu primeiro livro, publicado dois anos depois pela Editora Laterza, com o título "Poetica delle emozioni. I Bijagó di Bubaque (Guinea Bissau)". Nesse trabalho, dediquei-me à discussão de quanto as emoções que, em geral, são vistas como aquilo de mais íntimo, profundo, instintivo, natural entre seres humanos, na verdade são construídas socialmente. Investiguei como as vivências emocionais estavam implicadas na representação da pessoa entre os Bijagós, visto que não operam com base nas divisões cartesianas entre razão e emoção, corpo e mente. A pesquisa me possibilitou compreender que mesmo emoçóes complexas, como o ciúme, o amor, a raiva, não são universais, mas se declinam de forma muito diferente em outros contextos e esses achados eram muito fascinantes. Ao longo dos anos de pesquisa entre os Bijagós fui construindo ali relaçóes também de amizade muito significativas, a ponto de a experiência de ter trabalhado num contexto de vivência emocional tão diferente do meu se fazer sentir, anos mais tarde (eu já estava vivendo em Lisboa), quando começaram as grandes migraçôes para Portugal, inclusive de guineenses amigos meus.

Foi nesse momento - das grandes migraçôes para Portugal - que as relações entre migração, corpo e emoção passaram a se colocar como teus interesses de pesquisa?

Sim. Foi por meio das interlocuçôes com pessoas com quem me relacionei durante a pesquisa em Guiné-Bissau e que fizeram trânsitos migratórios para Portugal que comecei a investigar o sofrimento social, o mal-estar, o choque da migração e a busca por uma resposta terapêutica culturalmente competente e eficaz. A questão se pronunciou no contexto do sistema de saúde português que não estava preparado para dar essa resposta. Especificamente, passei a realizar investigaçóes em hospitais psiquiátricos, acompanhando casos de pessoas imigrantes que haviam sido internadas, às vezes de maneira coercitiva. $\mathrm{Na}$ pesquisa, eu buscava perceber quanto as sensaçóes de mal-estar eram compreendidas por meio de lógicas distintas - a dos interlocutores e a dos profissionais da saúde - e como essas diferentes formas de inteligir as emoções, o adoecimento, o cuidado podiam ter efeitos perversos, como a violência institucional. Isso porque, quando hospitalizadas em instituiçốes psiquiátricas, imediatamente essas pessoas eram codificadas como "pacientes" 
e, por isso, se tornavam objetos ou alvos de estratégias e dispositivos próprios do saber médico que os rotulavam, classificavam, diagnosticavam e patologizavam. Meu trabalho como antropóloga visava reconstruir as narrativas dessas pessoas na base do que elas mesmas diziam do mal-estar. Muitos falavam não de doença, mas de sofrimento e, no específico, de sofrimento social: falta de direitos e condiçóes básicas, exclusão, persecução pela polícia, discriminação racial. Algo que claramente cria mal-estar, dor, até sintomas de ansiedade, depressão e por aí afora; mas que, nitidamente, não se cura com psicofármacos. Eu percorria, com elas, os caminhos em direção a uma solução que, em suas perspectivas, teria sido eficaz. O ponto é que tais soluçốes, conhecidas como eficientes ou eficazes em seus contextos de origem, não tinham nada a ver com o tratamento farmacológico que estavam a receber. Ou seja, eu estava a contrapor uma leitura biomédica e uma leitura local do mal-estar, o que me conduziu a perceber em suas narrativas que a "origem" do sofrimento daquelas pessoas não podia ser localizada na biologia de seus corpos (como coloca a interpretação médica), mas nos processos que os levaram a decidir pela migração, a chegada a Portugal e a quebra da ilusão migratória diante da precariedade da vida, das condiçôes de trabalho e dos direitos de cidadania. Tratava-se de pessoas que se mexiam nos terrenos da violência estrutural. Nesse contexto, o diagnóstico psiquiátrico situava a patologia "no" indivíduo, esquecendo de todo o contexto no país de acolhimento e sua capacidade de desencadear possíveis mal-estares psicológicos. A condição de imigrante aprofundava essas forças sociais e políticas potencialmente patogênicas, pois viviam num país clandestinamente, sem direitos sociais, a ser olhado como um corpo estranho e não pertencente. Tratava-se, portanto, de um descolamento entre o corpo sujeito, ou seja, tu como te pensas e te sentes, e como os outros te veem: alguém diferente, inferior, suspeito, potencialmente criminoso, do qual ter medo. Alguém de quem se quer manter distante, afastado do centro e da vida das pessoas, às margens do "sistema" tanto simbólica quanto espacialmente em guetos que funcionavam como preservativos urbanos, os imigrantes acabavam por morar nas periferias de Lisboa.

Vejo aí duas questóes interessantes: a primeira diz respeito à tua própria condição de imigrante em Portugal; a segunda se refere às posições relacionais que tu e teus interlocutores de pesquisa assumiam, quando em Guiné-Bissau, e que parece ter havido novas tomadas de posiçóes quando vocês passam a se reencontrar em Portugal. Como você lidou com essas questóes em termos etnográficos?

Vou começar minha resposta pela segunda questão. O percurso de acompanhamento desses processos migratórios não foi, a princípio, uma questão etnográfica. Foi mais uma questão de amizades construídas nos quatro anos e meio em Guiné-Bissau. Portanto, mesmo pessoas que não conhecia diretamente chegavam em Lisboa e me procuravam na esperança de que eu ajudasse a arranjar habitação e trabalho. Então, no começo, era mais uma questão, como em qualquer fenômeno migratório, de ter redes de suporte no lugar de destino com coisas bem práticas que eu própria tive (e às vezes ainda tenho) que lidar, sendo imigrante cá, apesar de bem sabermos que a palavra imigrante se declina em milhares de nuances e de possibilidades de relação com órgãos estatais. Por isso, eu me 
tornei para essas pessoas, com quem mantive sempre relaçốes também de pesquisa, uma mediadora: eu alugava suas casas em meu nome e ajudava nos momentos iniciais de suas chegadas. Ao longo do percurso de acompanhamento e acolhimento desses amigos aqui em Lisboa, a etnografia se impôs a mim como uma necessidade política, uma urgência que mudou a minha forma de ver a própria construção da pesquisa. Não era apenas "algo interessante"! De alguma forma, a relação com pessoas que eu tinha conhecido em seu país de origem, no qual eu era a hóspede, e que, nas ocasióes em que estive com elas em Guiné-Bissau, buscaram me integrar e me acompanhar em seus mundos sociais, agora eram elas que estavam na condição de "hóspedes". Essa situação se colocou para mim como um espelho, o qual me deu uma noção muito nítida, mais do que eu havia tido até então, do meu privilégio social. É daí que emergiu a necessidade política de conduzir uma etnografia sobre suas experiências cá, pois na medida em que conheces teu privilégio (um privilégio branco, um privilégio europeu), conheces também a necessidade de usar esse privilégio de palavra, no fundo, para fazer uma ação. Apesar de se defender que a Antropologia não pode ser, apenas, denúncia, porque deves ter uma objetividade, uma cientificidade, eu sempre pensei que a coisa mais científica da minha forma de fazer Antropologia era eu me posicionar. É muito diferente fazer investigação sobre produção de cerâmicas, por exemplo, e fazer investigação sobre pessoas que não são atendidas em um hospital, porque não têm reconhecidos seus direitos por serem imigrantes. Nesses contextos de pesquisa, tem como não ser uma Antropologia politizada ou engajada? No fundo, dei-me conta que com a Antropologia podemos fazer algo para criar futuros melhores, despertar consciências, revelar o que geralmente é silenciado, chamar a atenção da sociedade a questóes sociais gritantes, mas das quais nem todos são conscientes. A partir disso, comecei a sentir a Antropologia como uma estratégia de chegar às decisões políticas, de despertar a opinião pública, de trazer à mesa as coisas que não se querem ver. Com relação à primeira questão, em meados dos anos 2000, houve uma nova vaga migratória em Portugal de pessoas oriundas de países como Ucrânia, Moldávia, ou seja, países do leste europeu que haviam acabado de entrar na União Europeia. Como podes imaginar, me olhando, são pessoas que têm, exatamente, meu fenótipo. Quando esses imigrantes, ainda hoje muito estigmatizados, chegaram a Portugal em massa criou-se uma clássica reação do tipo "nós" e "os outros". O mesmo ocorreu com a migração de brasileiros cá. Lembro-me que quando chegou a Portugal a vaga de mulheres brasileiras migrantes, especialmente as mineiras, criou-se um estereótipo da mulher brasileira como prostituta, sexualmente "fácil”, "acessível”. O mesmo aconteceu com as mulheres do Leste Europeu. Nesse amplo e difuso processo de estigmatização, os homens imigrantes dessa região da Europa foram socialmente categorizados como criminosos ligados a redes mafiosas e pessoas dependentes de álcool e outras drogas. Nesse contexto, eu comecei a ser lida e interpretada socialmente como uma mulher do Leste Europeu. Meu fenótipo não é, nos imaginários comuns, tipicamente italiano, mas, como cá dizem, é nitidamente "russo". A categoria "russo" é a etiqueta com a qual identificam todas essas populaçôes. Chamam-nas "as russas”, mas, manifestamente, declinam-se diversas populaçôes dessa categoria. Como isso me impactou? De repente, por exemplo, já ninguém falava comigo em lojas, nas ruas ou onde fosse me tratando por "você", mas por "tu”. Ou seja, meu valor social, o meu capital social diminuiu drasticamente. Mudou não só a pessoa verbal com a qual me tratavam, mas a atitude; era a liberdade que muitas pessoas, especialmente os homens, tomavam comigo, algo que antes não existia. Numa atitude abusiva, passaram 
a me tratar como mulher "fácil", corpo à sua mercê, a ponto de eu precisar recorrer a processos judiciais. No entanto, a possibilidade da queixa policial e de contratar uma advogada, obviamente, decorriam dos meus privilégios sociais, visto que nem todas as pessoas que sofrem discriminação social têm as condiçôes para se defender dessa maneira. Essas situações alçaram a pesquisa a outras etapas, porque uma coisa é observar e se incomodar com o que se passava aos meus amigos; outra coisa é seres tu agredida ou vítima de uma série de atitudes abusivas. No fundo, guardadas as especificidades que já indiquei aqui, te tornavas um corpo menos valioso. Foram nesses contextos nos quais a reflexividade se colocou de forma radical que comecei a pensar numa Antropologia que tinha de se posicionar. Pensar numa Antropologia posicionada politicamente é mostrar como as estruturas e os dispositivos sociais funcionam para incluir, mas, sobretudo, para afastar e estabelecer fronteiras porosas, ordinárias, cotidianas: quem passa essas fronteiras? Quais capitais se põem em jogo para ultrapassá-las? O que acontece quando se precisa acessar um serviço básico, como os serviços de saúde? Naquela altura, essas questôes começaram a se tornar intersticiais, uma vez que, ao acompanhar as experiências dos interlocutores em campo, fui dando-me conta que os fenótipos funcionavam como cortinas de fumaça que remetiam a diferenças socialmente construídas (raça, nacionalidade, classe social, gênero, capital corporal etc.) que definiam os trânsitos por entre essas fronteiras porosas e produziam identidades que conformavam (ou não) condições para esses trânsitos. Ou seja, na experiência de ser imigrante naquele contexto, a própria condição humana e, consequentemente, o acesso a direitos e à cidadania não se davam na base da paridade como, por vezes, se observa nos discursos estatais e nas leis. Do ponto de vista etnográfico, analisar esses processos em serviços de saúde foi bastante rentável.

Diante desse chamamento por uma Antropologia posicionada, você se vê vinculada academicamente ao campo da Antropologia Política, da Antropologia da Saúde ou com uma produção que faz esses campos dialogarem?

Eu diria que faço uma Antropologia da Saúde politizada. Ou uma Antropologia Médica crítica, dependendo das escolas e das nomenclaturas disciplinares de referência. Penso que qualquer tipo de estudo que tu fazes sobre contextos, situaçóes e pessoas que são historicamente subalternizadas, que estão sujeitas a representações estereotipadas, que estão às margens de um "sistema” cuja intenção não é integrá-las socialmente a sério; qualquer tipo de estudo, que seja sobre saúde, emoções, corpo, habitação, cidade, não deixa de ser político. São estudos que envolvem consciências e que podem produzir respostas científicas e políticas capazes de transformar as relaçôes sociais. A própria forma como nós, antropólogas, nos posicionamos em campo, ao lado das pessoas com quem realizamos nossas interlocuções de pesquisa, também é política, uma vez que realizamos uma coprodução de conhecimentos, pois trata-se de pessoas dotadas de voz, de conhecimentos, de palavras, são intelectuais - um bom exemplo disso são os ativistas - e produzem uma reflexão crítica sobre o que lhes passa no dia a dia. Ou seja, a produção do conhecimento antropológico é assentada numa dialogicidade, no sentido de que não sou eu, a antropóloga, que irei falar "pelas" ou "das" pessoas com quem desenvolvi a pesquisa. A pesquisa é um diálogo. Essa questão introduz aspectos éticos do fazer antropológico, principalmente aqueles que dizem respeito à legitimidade da antropóloga. No entanto, a Antropologia, como uma disciplina acadêmica, permite, em termos teórico-metodológicos, 
que nos aproximemos e nos afastemos das realidades que investigamos, de maneira que o fato de não fazeres parte do grupo social com o qual tu estás a trabalhar (pessoas com adoecimentos ou grupos sociais considerados como subalternizados) não quer dizer que, como pessoa e profissional, tu não tenhas a necessidade, outra vez, política, ou a urgência de te manifestar, pesquisar, escrever sobre um determinado tema. Até porque a bem ver na biografia de cada um de nós existem razões pelas quais essas questões são relevantes do ponto de vista mais íntimo e pessoal.

\section{Como está estruturado o campo da Antropologia da Saúde em Portugal?}

Em Portugal, a Antropologia da Saúde é um campo sólido, inclusive por ser um daqueles subcampos da Antropologia onde as questôes com as quais lidamos estão presentes de forma muito direta e perceptível na vida das pessoas. No âmbito da Antropologia da Saúde, tanto em Portugal como em outros países, é bastante fácil mostrar a importância que essa reflexão pode ter na melhora da eficácia terapêutica, da qualidade dos atendimentos, das políticas públicas. Todavia, em Portugal, a Antropologia da Saúde não é um campo tão grande. Existe uma escola, ligada a centros de investigação como o ICS/ULisboa e o Centro em Rede de Investigação em Antropologia (Cria), formada por colegas que criaram diferentes etapas desse diálogo entre Antropologia e Saúde: disciplinas nos cursos de graduação; programas de pós-graduação; grupos de pesquisa; e colaborações com instituições nacionais e estrangeiras. Apesar disso, ainda não existe um doutoramento específico em Antropologia da Saúde ou Antropologia Médica em Portugal. Há propostas nesse sentido que estão a se fermentar. Contudo, temos claramente diversos colegas que se ocupam de forma diferente dos problemas postos nesse campo científico: alguns se vinculam mais a perspectivas próprias da Antropologia Médica norte-americana; outros da Antropologia da Doença francesa; tem quem estuda a história da ciência médica ou a própria Biomedicina como um campo de saber-poder; e há aqueles que trabalham com questôes mais contemporâneas como migração, acolhimento em serviços públicos, refugiados, traumas, HIV/Aids e outras. Embora não sejamos muitos, há uma espécie de núcleo duro que conforma esse campo e um enorme interesse por parte de estudantes de doutorado. Há ainda uma variedade de percursos formativos das pessoas que atuam na Antropologia da Saúde portuguesa: alguns vêm de cursos de graduação na área da Saúde (Psicologia, Enfermagem, por exemplo) ou de outras disciplinas das ciências humanas e fazem a pós-graduação em Antropologia; e há os que fazem a graduação em Antropologia (em Portugal existe esta possibilidade) e desenvolvem todo o percurso acadêmico na mesma disciplina. Sobre financiamentos para pesquisa, em Portugal podemos dizer que, além de concursos internacionais extremamente competitivos com financiamentos europeus, a única agência estatal é a Fundação de Ciência e Tecnologia (FCT) do Ministério da Educação. A FCT abre, anualmente, concursos para seleção de projetos de pesquisa, mas os recursos são poucos. Em todo o mundo, a Antropologia está a ser marginalizada no nível de distribuição de financiamentos, justamente por esta questão que levantei antes: a distinção que as pessoas fazem entre quem "pensa" sobre as coisas e quem "faz" as coisas, o que nos coloca o desafio constante de demonstrar a relevância social do que fazemos e o impacto do que pensamos na realidade concreta. Ao nível nacional 
depende muito do momento político. Mudam-se os governos, muda-se a forma de apoiar (ou não) as Ciências Sociais, pois existe sempre aquele cunho crítico e político das nossas pesquisas, o que pode ser extremamente desconfortável àqueles que não querem lidar com os problemas sociais de forma objetiva, científica, eficiente e ainda mais incômodo quando quem está ao poder tem posturas fascistóides, como se vê no Brasil com o governo Bolsonaro.

Ainda em relação à Antropologia da Saúde, no Brasil há algumas distinções (não estanques) na maneira como os objetos de pesquisa são construídos por pesquisadores (antropólogos ou não) que atuam em departamentos de Saúde Coletiva e aqueles que atuam nos departamentos de Antropologia. Os primeiros tendem a tomar as questốes de saúde, doença e corpo como objetos em si mesmos (Antropologia "na" Saúde); enquanto os segundos partem dessas questóes para analisar problemas mais propriamente antropológicos (Antropologia “da” Saúde). No contexto português percebes se há esse tipo de distinção?

Essa divisão é mais nítida no Brasil, ao menos pelo que pude observar nas minhas experiências de trabalho em universidades como Universidade Federal do Rio Grande do Norte (UFRN) e Universidade de São Paulo (USP). Em Portugal não existe uma divisão tão evidente. Contudo, eu acho que há um esforço em integrar muito essas duas vertentes, pois uma Antropologia "da" Saúde, sem que esteja "na” saúde, corre o risco de ser demasiado teórica, ao que uma Antropologia "na" Saúde só voltada à formação de profissionais da saúde pode acabar por não ter um fundo teórico. Eu sempre pensei que uma Antropologia “da” Saúde tinha que estar "na” saúde e vice- versa. Eu, possivelmente, faço uma Antropologia "da” Saúde, contudo criei e dirigi cursos de pós-graduação para profissionais da saúde, da assistência social, da segurança pública, além de atuar constantemente em formaçóes para diferentes categorias profissionais que estão a exercer a própria profissão nos contextos que eu estudo como antropóloga. Nessas minhas experiências, tenho observado que, no fundo, eu não estou lá pra ensinar nada a eles. Estou lá para pensar com eles suas práticas, porque no dia a dia eles não têm esse tempo de se confrontar e discutir. Trata-se de um tempo extremamente precioso, porque são pessoas que vivem um trabalho com ritmos, com exigências, com tomada de decisões rápidas. Esses espaços e tempos formativos são importantes não só à eficácia de suas intervenções, mas nomeadamente ao bem-estar e às condições de trabalho dessas pessoas.

Desde 2018 estás a coordenar o projeto EXCEL. The Pursuit of Excellence. Biotechnologies, enhancement and body capital in Portugal (b). Quais as principais questôes teóricas com as quais tens lidado nesse projeto?

Sempre trabalhei com questóes sobre corpo, experiências e emoções; nomeadamente, as hierarquias de valor em torno do corpo: como o corpo é percebido, interpretado, julgado, imaginado, estereotipado, a ponto de se estabelecer socialmente quais corpos valem mais. Do ponto de vista fenomenológico, trata-se de experiências que põem a corporeidade no primeiro plano. No Projeto EXCEL, uma das questóes centrais são os usos estratégicos que as pessoas fazem do próprio corpo, como forma de fazerem

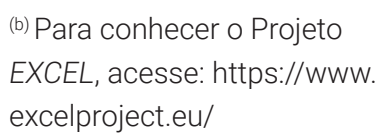

(b) Para conhecer o Projeto EXCEL, acesse: https://www. excelproject.eu/ 
mobilidades nessas hierarquiais corporais e terem melhor acesso a trabalho, habitação, saúde e outros direitos sociais. Ao longo dos anos, fui observando que as ações estatais operadas por profissionais de diversas áreas (saúde, assistência social, segurança pública, etc.), cujo objetivo era promover uma "educação" para tornar a vida das pessoas em posições sociais estruturalmente desfavorecidas mais "produtivas" ou "melhoradas", produziam diretivas (muitas vezes violentas) que terminavam por ser transformadas em valores, desejos, aspiraçóes, estratégias, investimentos para construir algo melhor para o futuro. Ao dizer investimentos, refiro-me não só àqueles de ordem "emocional”, mas, nomeadamente, a investimentos de dinheiro. Face à precariedade da vida e às mudanças políticas e econômicas constantes, as pessoas preferem investir em si mesmas, a "única garantia” que se tem. Tudo isso orientado por padróes hegemônicos que definem o que é um indivíduo de sucesso e que se movem por lógicas de diferenciações, de classificações e de hierarquizaçóes contínuas. Trata-se, portanto, de um fenômeno social no qual o investimento gera capital econômico que se transforma em outros capitais (simbólico, social, corporal ou somático, cultural). Esses padróes hegemônicos se espiralam em escalas variadas (global, nacional, local) e produzem subjetividades com base em marcadores sociais como gênero, geração, orientação sexual, identidade de gênero, classe social, nacionalidade, identificação racial ou étnica. Tudo isso compóe uma lógica de melhoramento (enhancement, em inglês): que tipo de pessoa tu queres ser? Quais são as tuas ambiçốes, teus desejos? O que estás disposto a fazer para ser uma "pessoa de sucesso"? Que tipo de mobilidade esses investimentos te proporcionarão no "mercado" matrimonial, relacional, profissional, social? Ao responder a essas questôes, as pessoas produzem narrativas sobre as formas de intervir na sua corporeidade com o objetivo de transformar seu capital somático em um corpo valioso. No Projeto EXCEL, portanto, estamos interessadas em diferentes estratégias para potenciar a memória, a concentração, o rendimento em tarefas, a produtividade, a lucidez, a performance sexual, a imagem corporal, etc. Muitas dessas estratégias são velhas conhecidas de pessoas que realizam trabalhos de alto rendimento e competividade - como nós, acadêmicos - em sociedades que estabelecem que ter ou não sucesso é uma responsabilidade de cada um. Ora, estamos diante das inflexões que o neoliberalismo avançado, com suas narrativas meritocráticas que desconsideram os condicionantes sociais, produz na vida cotidiana das pessoas. Nesse cenário, um dos focos do Projeto EXCEL é a indústria e o mercado das intervençôes cosméticas, bem como a centralidade do padrão de beleza eurocentrado nesse campo. Diante desse padrão de beleza, as pessoas com corpos não conformes ou dissidentes devem, de alguma forma, ou encontrar narrativas alternativas, ou tentar se conformar ao ideal. Entrevistei pessoas que investem na própria aparência face, muitas vezes, à ausência de outras estratégias, como me narrou uma mulher: "eu estudei pouco, não tenho capital cultural para vender. O que eu tenho é meu aspecto e com ele eu posso ascender a trabalhar aí e lá”. A aparência pode fazer toda a diferença entre trabalhar na cozinha de um fast food, sem contato com os clientes, e numa perfumaria a representar altas marcas de cosmética e a interagir com pessoas de estratos sociais mais altos. No trabalho de campo, entrevistei muitas mulheres negras que me explicaram como o mercado que se dirige a clientes maioritariamente brancos vende uma imagem estereotipada da beleza negra: a das modelos de passarela e de artistas como Beyoncé, Mariah Carey e Rihanna. Cabelos longos, brilhantes e fartos, peles aclaradas, corpos 
femininos magros e tonificados. A oferta da indústria cosmética dirigida a clientes que não se identificam como brancos é chamada de medicina estética "étnica", reproduzindo categorias que já deveriam ter sido desconstruídas e conceitos, como o de raça biológica, que já foram superados cientificamente. No centro de Lisboa, por exemplo, descobri um amplo mercado de produtos e tratamentos destinados à despigmentação da pele, alisamento de cabelos, extensóes capilares. A análise das condiçôes históricas e socioculturais do crescimento desse específico mercado, as dimensóes biopolíticas da beleza associadas à valorização da aparência europeia, as consequências sociais e os dilemas bioéticos associados à estética étnica tornaram-se então o centro das minhas preocupações. Qual a relação entre pigmentocracia, discriminação étnico-racial, exclusão social e práticas de branqueamento? Será o aclaramento da pele uma reação a atitudes discriminatórias, sentimentos de não adaptação e exclusão social? Quais as esperanças e as ambições de quem compra e utiliza substâncias para aclarar a pele, hoje, em Lisboa? Há também o melhoramento hormonal (como atrasar a menopausa ou interromper a menstruação), sexual (uso de Viagra, por exemplo), as tecnologias antienvelhecimento tanto para mulheres quanto para homens que envolvem o consumo de diferentes biotecnologias. Nesses casos, há uma lógica de modernidade, de sucesso, de corpo perfeito e que não muda, de libertação dos "limites" da biologia corporal. No fundo, essas intervenções cirúrgicas e substâncias (medicamentos, cremes, suplementos) refletem desejos construídos, como disse Michel Foucault, a partir de dispositivos e tecnologias - mais ou menos líquidas, plásticas, superficiais ou invasivas - que permitem alcançar o corpo que, socialmente, tem valor e que possibilita mobilidades no interior das hierarquias sociais. O melhoramento também se realiza por meio dos designs genéticos de embriões para criar seres humanos mais ajustados ao que consideramos, por exemplo, um filho perfeito. Estamos, pois, diante de um corpo-projeto em detrimento de um corpoferramenta. Por fim, destaco dois aspectos relevantes nesse cenário dos aprimoramentos: primeiro, nas últimas três décadas, houve um avanço nunca visto na história da humanidade em campos de conhecimento como genética, bioengenharia, medicina, biotecnologias, o que tem permitido possibilidades imensas de criação de técnicas de melhoramento; e, segundo, ao passo que a ambição pela perfeição tem aumentado, as tecnologias oferecidas no mercado têm se tornado, cada vez mais, economicamente acessíveis, contrariamente ao que fora na segunda metade do século 20. A despeito das evidências históricas e socioantropológicas de que o corpo humano sempre foi submetido a rigorosos esquemas de construção social, na contemporaneidade, a produção do corpo-projeto é cada vez mais possível graças às mediações biotecnológicas. Logo, o que me interessa nesta investigação são os ideais, as ambições, os desejos que levam as pessoas a fazerem isso ou aquilo em seus corpos e o que esperam agregar a suas vidas com isso. E perceber os determinantes sociais que orientam esses desejos e práticas que, muitas vezes, reproduzem formas de poder e de opressão, padróes hegemônicos severamente exclusivos, que violentam, patologizam, inferiorizam outras possibilidades de estar no mundo. Claramente, no meu trabalho dialogo sempre com as teorias feministas, antirracistas e anticapacitistas que ofereceram uma leitura das alteraçôes corporais, assim como dos padróes ideais que as inspiram, em termos de relaçóes de poder e discursos normativos, deslocando assim o foco do indivíduo para a dinâmica social em que estão enredados. 
Tendo em vista a amplitude de temáticas possíveis de serem incluídas no escopo das preocupaçôes do Projeto EXCEL, como tem sido feita a pesquisa de campo?

O Projeto EXCEL é desenvolvido por um coletivo de pesquisadores, no qual atuo como coordenadora. $\mathrm{O}$ trabalho de campo etnográfico que estamos a fazer é muito amplo, pois inclui pessoas, produtos tecnológicos e lugares, como: 1) farmácias e lojas de produtos alternativos ou naturais (incluindo plataformas comerciais na internet); 2) páginas e grupos em redes sociais on-line que reúnem pessoas interessadas em procedimentos estéticos diversos; 3) profissionais da estética e da medicina cosmética, bem como seus clientes; 4) estudantes de Medicina e suas estratégias de aprimoramento cognitivo com vistas a melhores desempenhos; e 5) interface entre consumidores, produtores e executores de tratamentos, de fármacos ou de processos por meio de um survey quantitativo ao nível nacional.

No Projeto EXCEL, como em outros, tens mantido relações com pesquisadores brasileiros. Como têm se dado essas relaçóes?

Essas relaçóes iniciaram por volta de 2006, quando conheci o professor Rubens Adorno (Faculdade de Saúde Pública da USP) num congresso de Antropologia da Saúde aqui em Portugal. Passado algum tempo, Rubens me convidou para estar na USP, em São Paulo, a dar disciplinas e a colaborar em pesquisas. Nessa ocasião, começamos a pensar e a construir projetos de pesquisas em conjunto sobre sofrimento social ao nível comparativo. Ter conhecido Rubens e estado em São Paulo naquele período, abriu-me as portas para outros contatos com colegas no Brasil. Depois disso tive colaborações pontuais com professores da Universidade Federal de Santa Caterina (UFSC), da Universidade Federal do Rio de Janeiro (UFRJ), da Universidade Estadual de Campinas (Unicamp), mas a minha maior experiência na Antropologia no Brasil, especialmente na docência, foi o contrato de professora visitante que tive com a UFRN, possível graças às minhas relaçóes com o professor Carlos Guilherme Octaviano do Valle. No caso do Projeto EXCEL, tenho trabalhado em parceria com Elaine Brandão (UFRJ) e com Fabiola Rohden (Universidade Federal do Rio Grande do Sul). Fabiola e eu temos realizado diversas atividades em conjunto, aliás em breve irá sair uma coletânea que relata um pouco este trajeto intelectual.

Nos teus projetos de pesquisa no campo da Antropologia da Saúde tens realizado interlocuções com outras Antropologias e outras formas de fazer etnografia. Podes comentar que Antropologias tens feito dialogar?

Já há um tempo que propus o que denominei de Ethnography-based Art e Artbased Ethnography. Por Ethnography-based Art entendo todo tipo de intervenção artística, em qualquer tipo de linguagem (visual, plástica, cinema, música, instalações, performance, etc.), baseada em um trabalho etnográfico e, portanto, site-specific. Essa metodologia é uma inspiração interessante para os artistas e uma ótima forma de comunicar os resultados de um trabalho acadêmico para uma população mais alargada. Pensando assim, fiz uma série de intervençôes juntamente com um coletivo que criei, o Coletivo Ébano - uma organização nômade, móvel, com participação de pessoas 
de diferentes nacionalidades e, por isso, atua a cá, no Brasil, nos Estados Unidos e em países de África. Como exemplo dos trabalhos que o Coletivo Ébano tem feito, posso listar um trabalho de iluminação artística urbana na Mouraria ${ }^{(c)}$, um bairro que, apesar de estar no centro de Lisboa, é associado a atividades ilícitas, à imigração, à prostituição. Já a Art-based Ethnography é quando tu usas a arte ou prática artística como metodologia para fazer a etnografia. A arte aqui já não é um instrumento de comunicação, mas uma estratégia para envolver as pessoas num projeto e para construir um trabalho em conjunto. É por meio desses trabalhos que dialogo com a Antropologia Urbana e em todos os projetos de pesquisa que desenvolvo incluo essas formas de fazer etnografia e de fazer arte como parte de suas metodologias, como forma de comunicar seus resultados para além dos nossos pares. No Projeto EXCEL também uso metodologias artísticas, colaboro com artistas e no final teremos um percurso expositivo no Museu da Cidade, em Lisboa.

Chiara, para finalizarmos, é notório quanto a etnografia ganhou uma centralidade ao longo de toda nossa conversa. Poderias comentar a esse respeito?

Sabemos que o método etnográfico é justamente o que caracteriza a Antropologia enquanto disciplina acadêmica e profissão e o que a distingue das outras Ciências Sociais. Ou seja, a etnografia é própria da nossa preparação teórico-metodológica e do nosso empenho em estar em campo, onde trabalhamos de forma prolongada, densa, profunda, criativa, e de como, por meio desse fazer, produzimos um conhecimento o mais qualitativo possível. Para mim, a riqueza que a Antropologia oferece como disciplina é mesmo, em comparação às outras, a possibilidade de ter uma aproximação à experiência dos sujeitos com os quais trabalhamos e construímos esse saber. Assim, a observação participante é extremamente densa, eu diria mesmo que é uma "imersão participante”, pois tentamos nos aproximar o mais possível das questóes que as pessoas querem levantar conosco em nossos diálogos. Por isso, de forma muito nítida, a etnografia atravessa todo o meu percurso, entendendo que ela se declina em diferentes tipos e formas. Além disso, gosto de pensar no gesto etnográfico do ponto de vista teórico, considerando as diversas fases do processo de construção do conhecimento, as possíveis soluções metodológicas, a questão da validade e da autoridade científica. Em Antropologia, concebemos e praticamos a etnografia de maneira bastante peculiar em termos de investimento de tempo, nas relaçóes dialógicas que construímos em campo com as pessoas, isto é, não estamos a falar de relações entre pesquisadores e sujeitos. Como bem sabemos, ao se fazer etnografia não estamos a impor à pessoa o diálogo. São as pessoas que nos permitem, ou não, fazer etnografia na medida em que aceitam, ou se recusam, a dialogar conosco. Portanto, quando uma pessoa com quem construístes interlocuçóes em campo te abre espaço em sua vida e em seu mundo social, te dedica seu precioso tempo e póe-se a conversar contigo, ela é autora, junto contigo, da reflexão e do saber que estão a criar. Esse elemento colaborativo ou participativo é próprio do conhecimento antropológico, pois, diferente de outras disciplinas, não estamos a pensar sobre as pessoas, mas com elas! (c) Para conhecer o Coletivo Ébano e seus projetos, acesse: https://www.ebanocollective.org/ 


\section{Financiamento}

A pesquisa e a estadia em Lisboa foram financiadas pela Fundação de Amparo à Pesquisa do Estado de São Paulo (Fapesp) no âmbito do projeto "Sofrimento social e ajuda mútua entre pessoas que vivem com HIV/Aids em uma rede social na internet” (Processo n.

2018/07846-6), desenvolvido durante os anos 2018 e 2020.

\section{Conflito de interesse}

$\mathrm{O}$ autor não tem conflito de interesse a declarar.

\section{Direitos autorais}

Este artigo está licenciado sob a Licença Internacional Creative Commons 4.0, tipo BY (https://creativecommons.org/licenses/by/4.0/deed.pt_BR).

\section{(cc) BY}

\section{Editor}

Antonio Pithon Cyrino

Editor associado

Pedro Paulo Gomes Pereira

\section{Submetido em}

27/01/21.

Aprovado em

$17 / 02 / 21$.

\section{Referência}

1. Peirano M. Etnografia não é método. Horiz Antropol. 2014; 20(42):377-91. Doi: https://doi.org/10.1590/s0104-71832014000200015. 